\title{
Gene-based interaction analysis shows GABAergic genes interacting with parenting in adolescent depressive symptoms
}

\author{
Citation for published version (APA):
}

Van Assche, E., Moons, T., Cinar, O., Viechtbauer, W., Oldehinkel, A. J., Van Leeuwen, K., Verschueren, K., Colpin, H., Lambrechts, D., Van den Noortgate, W., Goossens, L., Claes, S., \& van Winkel, R. (2017). Gene-based interaction analysis shows GABAergic genes interacting with parenting in adolescent depressive symptoms. Journal of Child Psychology and Psychiatry, 58(12), 1301-1309. https://doi.org/10.1111/jcpp.12766

Document status and date:

Published: 01/12/2017

DOI:

10.1111/jcpp. 12766

Document Version:

Publisher's PDF, also known as Version of record

\section{Document license:}

Taverne

Please check the document version of this publication:

- A submitted manuscript is the version of the article upon submission and before peer-review. There can be important differences between the submitted version and the official published version of record.

People interested in the research are advised to contact the author for the final version of the publication, or visit the DOI to the publisher's website.

- The final author version and the galley proof are versions of the publication after peer review.

- The final published version features the final layout of the paper including the volume, issue and page numbers.

Link to publication

\footnotetext{
General rights rights.

- You may freely distribute the URL identifying the publication in the public portal. please follow below link for the End User Agreement:

www.umlib.nl/taverne-license

Take down policy

If you believe that this document breaches copyright please contact us at:

repository@maastrichtuniversity.nl

providing details and we will investigate your claim.
}

Copyright and moral rights for the publications made accessible in the public portal are retained by the authors and/or other copyright owners and it is a condition of accessing publications that users recognise and abide by the legal requirements associated with these

- Users may download and print one copy of any publication from the public portal for the purpose of private study or research.

- You may not further distribute the material or use it for any profit-making activity or commercial gain

If the publication is distributed under the terms of Article 25fa of the Dutch Copyright Act, indicated by the "Taverne" license above, 


\title{
Gene-based interaction analysis shows GABAergic genes interacting with parenting in adolescent depressive symptoms
}

\author{
Evelien Van Assche, ${ }^{1,2}$ (D) Tim Moons, ${ }^{1,3}$ Ozan Cinar, ${ }^{4}$ Wolfgang Viechtbauer, ${ }^{4}$ \\ Albertine J. Oldehinke1, ${ }^{5,6}$ Karla Van Leeuwen, ${ }^{7}$ Karine Verschueren, ${ }^{8}$ Hilde Colpin, ${ }^{8}$ \\ Diether Lambrechts, ${ }^{9,10}$ Wim Van den Noortgate, ${ }^{11}$ Luc Goossens, ${ }^{8}$ Stephan Claes, ${ }^{1,2}$ and \\ Ruud van Winke1 ${ }^{12}$
}

${ }^{1}$ GRASP-Research Group, Department of Neuroscience, KU Leuven, Leuven, Belgium; ${ }^{2}$ University Psychiatric Center, KU Leuven, Leuven, Belgium; ${ }^{3} \mathrm{OPZ}$ Geel, Geel, Belgium; ${ }^{4}$ Department of Psychiatry and Neuropsychology, School for Mental Health and Neuroscience, Maastricht University, Maastricht, The Netherlands; ${ }^{5}$ University Medical Center Groningen, Groningen, The Netherlands; ${ }^{6}$ Interdisciplinary Center Psychopathology and Emotion Regulation, University of Groningen, Groningen, The Netherlands; ${ }^{7}$ Parenting and Special Education Research Unit, Faculty of Psychology and Educational Sciences, KU Leuven, Leuven, Belgium; ${ }^{8}$ School Psychology and Child and Adolescent Development Research Unit, Faculty of Psychology and Educational Sciences, KU Leuven, Leuven, Belgium;

${ }^{9}$ Vesalius Research Center, VIB, Leuven, Belgium; ${ }^{10}$ Laboratory for Translational Genetics, Department of Oncology, KU Leuven, Leuven, Belgium; ${ }^{11}$ Department of Methodology of Educational Sciences, Faculty of Psychology and Educational Sciences, KU Leuven, Leuven, Belgium; ${ }^{12}$ Department of Neuroscience, Center for Contextual Psychiatry, KU Leuven, Leuven, Belgium

\begin{abstract}
Background: Most gene-environment interaction studies $(G \times E)$ have focused on single candidate genes. This approach is criticized for its expectations of large effect sizes and occurrence of spurious results. We describe an approach that accounts for the polygenic nature of most psychiatric phenotypes and reduces the risk of false-positive findings. We apply this method focusing on the role of perceived parental support, psychological control, and harsh punishment in depressive symptoms in adolescence. Methods: Analyses were conducted on 982 adolescents of Caucasian origin $\left(M_{\text {age }}(S D)=13.78(.94)\right.$ years) genotyped for 4,947 SNPs in 263 genes, selected based on a literature survey. The Leuven Adolescent Perceived Parenting Scale (LAPPS) and the Parental Behavior Scale (PBS) were used to assess perceived parental psychological control, harsh punishment, and support. The Center for Epidemiologic Studies Depression Scale (CES-D) was the outcome. We used gene-based testing taking into account linkage disequilibrium to identify genes containing SNPs exhibiting an interaction with environmental factors yielding a $p$ value per single gene. Significant results at the corrected $p$-value of $p<1.90 \times 10^{-4}$ were examined in an independent replication sample of Dutch adolescents $(N=1354)$. Results: Two genes showed evidence for interaction with perceived support: GABRR1 $\left(p=4.62 \times 10^{-5}\right)$ and GABRR2 $\left(p=9.05 \times 10^{-6}\right)$. No genes interacted significantly with psychological control or harsh punishment. Gene-based analysis was unable to confirm the interaction of GABRR1 or GABRR2 with support in the replication sample. However, for GABRR2, but not GABRR1, the correlation of the estimates between the two datasets was significant $(r(46)=.32 ; p=.027)$ and a gene-based analysis of the combined datasets supported GABRR2 $\times$ support interaction $\left(p=1.63 \times 10^{-4}\right)$. Conclusions: We present a gene-based method for gene-environment interactions in a polygenic context and show that genes interact differently with particular aspects of parenting. This accentuates the importance of polygenic approaches and the need to accurately assess environmental exposure in $\mathrm{G} \times \mathrm{E}$. Keywords: Gene-environment interaction; polygenic; parenting; gene-based testing; adolescents; depression.
\end{abstract}

\section{Introduction}

Depression in adolescence remains a major concern, both for its concurrent implications and its risk for psychopathology and impaired well-being in adulthood (Lahey, 2015; McLeod, Horwood, \& Fergusson, 2016). It is widely assumed that depression, along with other psychiatric disorders, has a polygenic basis (Ripke et al., 2013; Smoller et al., 2013). However, in contrast to schizophrenia, few studies have been successful yet in identifying genome-wide significant markers for depression (Flint \& Kendler, 2014; Hyde et al., 2016; Levinson et al., 2014).

Conflict of interest statement: No conflicts declared.
The paucity of robust genetic findings may be due to the involvement of environmental stressors in depression and, subsequently, the lack of methods that integrate these environmental stressors in a polygenic context (Levinson et al., 2014; Ripke et al., 2013). Gene-environment interactions $(G \times E)$ are expected to be important in the field of psychiatry, as phenotypes are typically characterized by an interplay of environmental stressors and a biological genetic-predisposition. $\mathrm{G} \times \mathrm{E}$ is often seen as a first step into this etiological complexity (Zannas \& Binder, 2014). Polygenic gene-environment interaction studies may fill this gap (Plomin, 2013; Ripke et al., 2013; Winham \& Biernacka, 2013). So far, most $\mathrm{G} \times \mathrm{E}$ research has focused on single genes or a 
limited number of genetic markers (Caspi et al., 2003; Dunn et al., 2011), which fails to grasp the underlying polygenic architecture of psychiatric disorders such as depression. In their review on candidate genes in $\mathrm{G} \times \mathrm{E}$ research, Duncan and Keller (2011) criticized the risk of spurious findings, as well as the expectations of single variants with large effect sizes. This is indeed not supported by the current GWAS literature, showing that many SNPs contribute simultaneously to the phenotype (Purcell et al., 2009; Smoller et al., 2013). In their efforts to understand the complexity of psychiatric phenotypes at a polygenic level, researchers have turned to polygenic risk scores (Purcell et al., 2009; Wray et al., 2014). These scores allow for a combined risk assessment of multiple polymorphisms that collectively explain a larger part of the genetic susceptibility for complex disorders (Manolio et al., 2009; Plomin, 2013). However, in a polygenic context, it can be expected that multiple genes interact with different environmental aspects (Viding, 2013), highlighting two concerns with the current application of polygenic risk scores in $\mathrm{G} \times \mathrm{E}$ research. First, the polygenic scores are often constructed based on the main effects of SNPs, and the interaction of the polygenic score with the environment is analyzed subsequently (Peyrot et al., 2015; Vinkhuyzen \& Wray, 2014). This assumes that genes, important for the main effect, are equally important in the interaction, which is not necessarily the case. Although different exposures are likely to require different polygenic risk scores, the approach of a 'stress-sensitivity score' as a genetic endophenotype, may thus be an important step forward in the field of $\mathrm{G} \times \mathrm{E}$ (Keers et al., 2016). Second, the primary goal of $\mathrm{G} \times \mathrm{E}$ research is not to identify risk genes (for which GWAS is a superior approach), but rather unraveling the biological processes through which environmental factors may impact disease risk (van Winkel, 2015). As the polygenic risk score is an overall measure of disease risk, it is unclear which specific genes or biological pathways interact with specific aspects of the environment, preventing the incorporation of $\mathrm{G} \times \mathrm{E}$ as an aid for reliable stratification or a useful tool in understanding the etiological processes involved in the development of psychopathology.

We describe a method to examine statistically significant findings within genes, taking into account the linkage disequilibrium (LD) structure of the gene. With this method, we explore the involvement of multiple genes in adolescent depressive symptoms, as they interact with perceived parenting, focusing on perceived parental support, psychological control, and harsh punishment. Our previous work, along with other research, has shown that these parenting variables are strongly correlated with depressive symptoms, the first one negatively, and the latter two positively (B. D. McLeod, Weisz, \& Wood, 2007; Van Assche et al., 2016). At the level of genetic variation, we use an extended candidate gene approach with 263 different genes known to be involved in neurotransmission, represented by 4,947 SNPs. Our expectation was that different genes would interact with different perceived parenting aspects in explaining depressive symptoms in adolescents.

\section{Methods \\ Sample characteristics}

The analyses presented in this paper use data from the STRATEGIES project (acronym for Studying Transactions in Adolescence: Testing Genes in Interaction with Environments). From an original sample of 1,111 adolescents (mean age: 13.79 years, $S D=.93,51 \%$ boys), $1,103(99 \%)$ agreed to participate in the genetic part of the study. The adolescents were recruited from nine schools situated in Flanders, Belgium. After genotyping quality control, the sample comprised 1,031 adolescents. The quality control steps are discussed in detail in the supplementary data, available online. Ancestry was assessed asking about grandparents' country of birth. Only the adolescents with reported Caucasian ethnicity $(n=982)$ were included in the analyses described in this manuscript.

Ethical considerations: both parents and adolescents gave written consent for the use of psychological data and DNA sampling. The study protocol was approved by the biomedical Internal Review Board of KU Leuven, Leuven, Belgium.

The TRAILS dataset $(N=1,354 ; 48 \%$ boys) was used for replication analysis (Oldehinkel et al., 2015). We used the data from wave 2 for the replication of the main effect, as the age was closest with our data (mean age: 13.02 years). Parenting was only available at wave 1 (mean age: 10.58 years). Therefore, these data were used in order to replicate the $\mathrm{G} \times \mathrm{E}$ results.

\section{Depressive symptoms and perceived parenting}

The Center for Epidemiologic Studies Depression Scale (CES-D Scale) was used to measure depressive symptoms and was scored according to the developers' guidelines (Radloff, 1977). Scores range from 0 to 60 with higher scores reflecting higher levels of depressive symptoms. As we are focusing on the prevalence of depressive symptoms in an adolescent population sample, we handle the scores as a continuous measure. This implies that we cannot draw conclusions on the psychiatric diagnosis of major depressive disorder (MDD).

All adolescents were asked to complete self-report questionnaires regarding multiple aspects of perceived parenting. This 65-item questionnaire comprised 10 different subscales, which are discussed in detail in the supplementary information. Adolescents responded using a 5-point Likert-type rating scale ranging from $1=$ (almost) never to $5=$ (almost) always. A factor analysis with these 10 subscales yielded five factors: perceived parental support, proactive control, psychological control, punishment, and harsh punishment. A full description of the subscales and statistical aspects of the factor analysis can be found in Janssens et al.(2015). For the present manuscript, only the three perceived parenting variables $(E)$ with a significant association with reported depressive symptoms in our previous research (Table 1; Van Assche et al., 2016) were selected for analysis: perceived support (PS, e.g. 'My parents encourage me to find my own direction'), perceived psychological control (PPC, e.g. 'My parents make me feel guilty when I did something wrong'), and perceived harsh punishment (PHP, e.g. 'My parents slap me when I did something wrong'). 
The TRAILS dataset used the revised child anxiety and depression scale (RCADS; Chorpita, Yim, Moffitt, Umemoto, \& Francis, 2000). As our outcome of interest is depressive symptoms, we only used the 10-item depression subscale. Parenting was assessed in the TRAILS dataset by the EMBU-C (Markus, Lindhout, Boer, Hoogendijk, \& Arrindell, 2003). Table 2 provides demographic information on the two samples. We used a factor analysis to identify items that were closest to the ones assessed in our primary sample. We selected items assessing perceived parental responsiveness and autonomy (for details, see supplementary data). We included nine items of the EMBU-C scale that showed a loading of minimum 0.45 on the first factor and on no other factor with more than 0.20 . Our selection of items showed a high correlation with the original emotional warmth subscale $(r(1,326)=.93$, $\left.p<2 \times 10^{-16}\right)$.

\section{SNPs, genotyping, and QC}

The setup of the study was based on known neurotransmitterrelated protein interaction networks (Franceschini et al., 2013) of the phenotype (depressive symptoms) and genetic variants known to be involved in neurotransmission. We selected 344 genes involved in nine neurotransmitter pathways: serotonin, dopamine, HPA-axis, oxytocin, GABA, glutamate, choline, noradrenergic neurotransmission, and the clock pathway. For each gene, we selected tagging SNPs to reveal the LDstructure of the gene (using Haploview (Barrett, Fry, Maller, \& Daly, 2005)), as well as a number of SNPs known from previous candidate SNP work (e.g. rs25531(SLC6A4), rs6265(BDNF), and rs4680(COMT)). A total of 7,043 SNPs were genotyped for all 1,103 individuals.

We followed the protocol of Anderson et al.(2010) and the supplementary data from Purcell et al.(2009) as a guideline for quality control, adapting the specificities for a case-control design to a continuous phenotype. After quality control, the dataset comprised 5,052 SNPs for 1,031 individuals. For the statistical analysis, only genes with three or more SNPs were selected (i.e. 263 genes with 4,947 SNPs). Details are described in the supplementary data.

\section{Statistical analysis}

The statistical analyses were conducted using R (v3.2.4. R Development Core Team, 2008). Linear regression analyses were conducted to examine the interaction of each SNP (G) with the three selected environmental variables (E) respectively in explaining depressive symptoms (CES-D, log-transformed). All analyses are controlled for gender (dummy coded) and age. Further statistical details can be found in the supplementary information. Following recent guidelines for $\mathrm{G} \times \mathrm{E}$ testing, proper control of potential confounders requires adding the interaction between each confounder and the $G$ and $E$ variables to the model (Keller, 2014). SNPs were coded for additive testing as recommended (Cantor, Lange, \& Sinsheimer, 2010; Hill, Goddard, \& Visscher, 2008; more information on the allele coding is available upon request). Because all non-Caucasian adolescents were excluded from analysis, we did not correct for ancestry in our final model.

For the second stage of the analysis, we extracted the estimated coefficient, test statistic, and $p$-value for $\beta_{4}$ (i.e. the $\mathrm{G} \times \mathrm{E}$ interaction term; $\beta_{1}$ for the main effect analysis) for each SNP. SNPs were annotated to the 263 genes using Ensembl and BioMart (Curwen et al., 2004; Smedley et al., 2015). We then used gene-based testing to identify genes with SNPs showing an interaction with the environmental variable by pooling the $p$-values for all SNPs in the same gene. Standard methods for combining the results of multiple tests (e.g. Fisher, 1932) cannot be used for this purpose, because these methods typically assume that the tests are independent. In the present case, we know that the SNPs are not independent due to linkage disequilibrium (LD). Therefore, we used Brown's method (Brown, 1975) for the combination of the tests (i.e. an extension of Fisher's method), which allows for dependency between the tests to be combined. Hence, we obtained the LD correlation matrices for all SNPs (using PLINK v1.07; Purcell et al., 2007) and applied Brown's method to obtain a test per gene with correction for linkage disequilibrium. A more detailed description of Brown's method is provided in the Section 3 in Appendix S1. The approach presented does not allow the researchers to evaluate the direction of the effect at

Table 1 Characteristics of the environmental variables

\begin{tabular}{llll}
\hline & \multicolumn{1}{c}{ PS } & \multicolumn{1}{c}{ PPC } & \multicolumn{1}{c}{ PHP } \\
\hline Median; Mean $(S D)$ & $4.01 ; 3.91(.64)$ & $1.74 ; 1.88(.64)$ & $.31(.054)$ \\
Regression coeff. (SE) & $-.42(.040)$ & $.50(.039)$ & 5.86 \\
$t(980)$ & -10.50 & 12.67 & $6.41 \times 10^{-9}$ \\
$p$-value & $<2 \times 10^{-16}$ & $<2 \times 10^{-16}$ & .033 \\
Adjusted $R^{2}$ & .10 & .14 & $r(980)=-.31$ \\
Correlation PS & & $r(980)=-.58$ & -.36 to $-.25\left(<2 \times 10^{-16}\right)$ \\
$95 \%$ CI $(p$-value) & & -.61 to $-.53\left(<2 \times 10^{-16}\right)$ & $r(980)=.54$ \\
Correlation PPC & & $.49-.58\left(<2 \times 10^{-16}\right)$ \\
95\% CI ( $p$-value) & & & \\
\hline
\end{tabular}

Perceived support (PS), perceived psychological control (PPC) and perceived harsh punishment (PHP) in association with reported depressive symptoms (CES-D) and their internal correlations.

Table 2 Demographic information on the STRATEGIES dataset, as well as TRAILS' wave 1 and wave 2

\begin{tabular}{lccr}
\hline & Trails wave 1 & Trails wave 2 & STRATEGIES \\
\hline$N$ (Mean age) & $1354(10.58$ years) & $1354(13.02$ years) & $982(13.79$ years) \\
Depression score: Mean $(S D)$ & $6.29(3.22)$ & $4.32(3.60)$ & $10.85(9.32)$ \\
Depression score: Median $(/ \max )$ & $6(/ 30)$ & $4(/ 30)$ & $8(/ 60)$ \\
Mean parental support $(S D) / \max$ & $3.18(.58) / 4$ & $\mathrm{X}$ & $3.91(.64) / 5$ \\
Mean psych. contr. $(S D) / \max$ & $1.61(.35) / 4$ & $\mathrm{X}$ & $1.88(.64) / 5$ \\
Imputed SNPs for the 3 genes of interest (tot $=111)$ & European ancestry (NL) & & European ancestry (BE) \\
\hline
\end{tabular}


the gene level: the gene-based interaction gives an overall estimate. To address this issue, we highlighted the most significant SNP in the gene and added a figure showing the actual direction of the estimates (Section 6 in Appendix S1).

Finally, we applied Bonferroni correction to the gene-based $p$-values for the number of genes tested (263 genes, cut-off for correction: $\left.p<1.90 \times 10^{-4}\right)$. Results of all 263 genes tested for $\mathrm{G} \times \mathrm{E}$ are available upon request. Figure 1 represents a summary of the applied method.

A power analysis conducted prior to analysis showed that a sample size of $N=800$ had more than $80 \%$ power for detecting small environmental effects, genetic effects, and $\mathrm{G} \times \mathrm{E}$ interactions that each accounted for only $1 \%$ of the variance with $\alpha=.05$.

\section{Replication analysis}

We analyzed genes that were significant in our primary analysis (GRID2IP, GABRR1, and GABRR2) using the exact same SNPs from the imputed TRAILS dataset as in our primary analysis. The replication analysis was conducted in three steps. First, we performed the same gene-based significance test as used in the primary analysis. Second, in line with the sign test (Ripke et al., 2013), we investigated the correlation between the beta estimates of the two samples. Third, to increase power, we combined both datasets and repeated the gene-based test, now with a sample consisting of $58 \%$ replication set and $42 \%$ primary dataset; correcting the model additionally for sample of origin. Details are provided in the supplementary materials.

\section{Results \\ Descriptive statistics and main effects of environmental variables}

CES-D scores ranged from 0 to 54 (Median $=8$, Mean $(S D)=10.86(9.32))$. The scores followed an approximately normal distribution following log- transformation $($ Mean $(S D)=2.16(.85))$. In the present sample, $23.5 \%$ of the adolescents $(n=231)$ reported a score of 16 or higher. As summarized in Table 1 , perceived psychological control and harsh punishment are positively associated with reported depressive symptoms (PPC: Estimate $=.50, t(980)=12.67, p<$ $2 \times 10^{-16} ; \quad$ PHP: Estimate $=.31, \quad t(980)=5.86$, $\left.p=6.41 \times 10^{-9}\right)$, and perceived support is negatively associated $\quad($ Estimate $=-.42, t(980)=-10.50, p<$ $\left.2 \times 10^{-16}\right)$. Age and gender were significantly associated with depressive symptoms $(r(979)=.077$, $p=.016$ and ANOVA: $F(1,980)=8.97, p=.0028$, respectively), and with the perceived parenting dimensions (age: PS: $r(973)=-.17, p=4.04 \times 10^{-8}$; PPC: $r(973)=.12, \quad p=7.3 \times 10^{-5} ;$ PHP: $r(973)=-.082$, $p=.011$; gender: PS: $F(1,980)=11.39, p=.00077$; PPC: $F(1,980)=9.73, p=.0019$; PHP: $F(1,980)=9.71$, $p=.0019)$. Girls reported more depressive symptoms and higher support, but lower psychological control and harsh punishment. Perceived support was negatively correlated with perceived psychological control and harsh punishment, perceived psychological control and harsh punishment were positively correlated (Table 1).

\section{Genetic analyses and interaction effects}

Genetic main effects. The effect of the glutamaterelated gene GRID2IP (glutamate receptor, ionotropic, delta2-interacting protein) on depressive symptoms was significant $\left(p=3.30 \times 10^{-5} ; 11 / 23\right.$ SNPs with $p<.05)$. This was the only gene effect surviving Bonferroni correction for the main effect. The most significant SNP in the gene was rs11773436 (Estimate $=-.11 ; \quad t(977)=-2.96$;

(A) Gene-based Tests of Perceived Support x 5052 SNPs (Correction for 5052 SNPs: 9.90e-06)

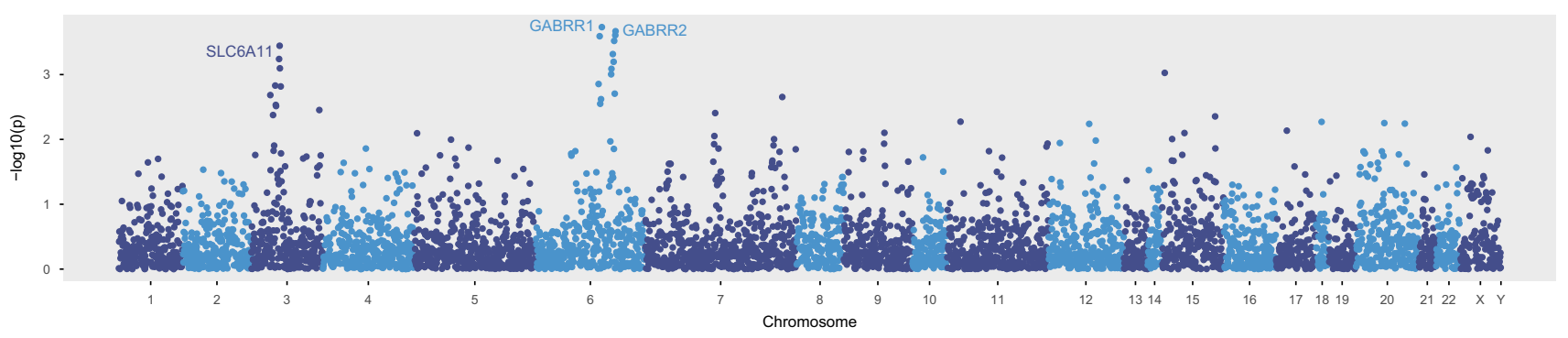

(B) Perceived support x 263 genes (Correction for 263 Genes: 1.90e-04)

(C) Perceived Support x rs2064831 (GABRR2)
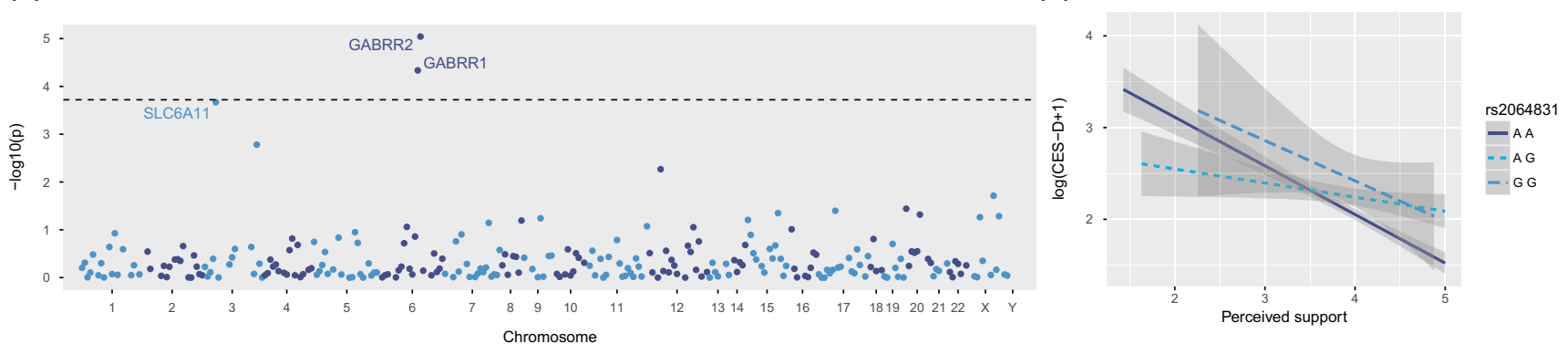

Figure 1 Gene-based testing for gene-environment interactions. (A) Manhattan plot showing $p$-values for all 5052 SNPs in interaction with perceived support (Bonferroni: $9.90 \times 10^{-6}$ ). (B) Gene-based $p$-values for the 263 genes in interaction with perceived support (Bonferroni: $1.90 \times 10^{-4}$ ). (C) Interaction of the most significant SNP of the most significant gene [Colour figure can be viewed at wileyonlinelibrary.com] 
$p=3.10 \times 10^{-3}$; risk allele: $G$ ). Although the gene was not significant at the gene-based level in the replication analysis $(p=.39)$, we found a strong and significant correlation between the estimates of our sample and the estimates of the replication sample $(r$ $\left.(21)=.68, \quad p=3.37 \times 10^{-4}\right)$. Furthermore, combined analysis of both samples revealed a genebased significance level of $p=9.27 \times 10^{-5}$, well below the preset cut-off $\left(p=1.90 \times 10^{-4}\right)$.

Genetic interactions with perceived PS. Genebased testing was significant for two GABA-related genes in interaction with perceived parental support (Table 3 and Figure 2): GABRR2 (GABA A-receptor rho2; $p=9.05 \times 10^{-6}$ ) and GABRR1 (GABA Areceptor rho $1 ; p=4.62 \times 10^{-5}$ ). In the replication analyses, none of the gene-based interaction results were significant (lowest $p$-value: GABRR2; $p=.15$ ). However, for $G A B R R 2$, the correlation of estimates between the replication set and the primary dataset was marginally significant: $r(46)=.32, p=.027$. Moreover, the significance of the gene-based analysis in the combined dataset was significant $\left(p=1.63 \times 10^{-4}\right)$. GABRR 1 and GABRR2 are in the same region of chromosome 6; however, there was no evidence for SNPs in LD between both genes (Section 4 in Appendix S1).

Genetic interactions with PPC and PHP. None of the genes interacted significantly with perceived psychological control or physical punishment. Post hoc analyses without the correcting covariate interaction terms (Keller, 2014) did not meaningfully change the results. Section 5 in Appendix S1 shows the top five genes in interaction with the different environmental variables.

\section{Discussion}

In line with the ongoing search for methods facilitating researchers to grasp the multifactorial nature

Table 3 Significant genes and SNPs

\begin{tabular}{|c|c|c|}
\hline Gene & GABRR2 & $G A B R R 1$ \\
\hline Genomic location & $6 q 15$ & $6 q 15$ \\
\hline$p$-value gene level & $p=9.05 \times 10^{-6}$ & $4.62 \times 10^{-5}$ \\
\hline $\begin{array}{l}\text { SNPs } p<.05 / \\
\text { SNPs in gene }\end{array}$ & $14 / 48$ & $6 / 40$ \\
\hline \multicolumn{3}{|c|}{ SNPs in $\mathrm{G} \times \mathrm{E}$ interaction } \\
\hline $\begin{array}{l}\text { Most } \\
\text { significant SNP }\end{array}$ & rs2064831 & rs1186902 \\
\hline$p$-value & $2.26 \times 10^{-4}$ & $1.37 \times 10^{-4}$ \\
\hline $\begin{array}{l}\text { Regression } \\
\text { coeff. }(t \text {-value; } d f)\end{array}$ & $.29(3.70 ; 971)$ & $-.26(-3.83 ; 970$ \\
\hline $\begin{array}{l}\text { Adjusted } R^{2} \\
p \text {-value }\end{array}$ & $\begin{array}{l}.14 \\
p<2 \times 10^{-16}\end{array}$ & $\begin{array}{l}.13 \\
p<2 \times 10^{-16}\end{array}$ \\
\hline$F(d f)$ & $18.92(9,971)$ & $17.72(9,970)$ \\
\hline HWE ( $p$-value) & .51 & .50 \\
\hline $\begin{array}{l}\text { rGE (ANOVA); } \\
p \text {-value }\end{array}$ & $\begin{array}{c}F(2,979)=.027 \\
p=.97\end{array}$ & $\begin{array}{c}F(2,978)=.42 \\
p=.66\end{array}$ \\
\hline
\end{tabular}

Significant genes in interaction with perceived support (PS) and perceived psychological control (PPC), respectively. The SNP reported in the second part of the table is the most significant SNP of the gene in interaction with the environmental parameter.
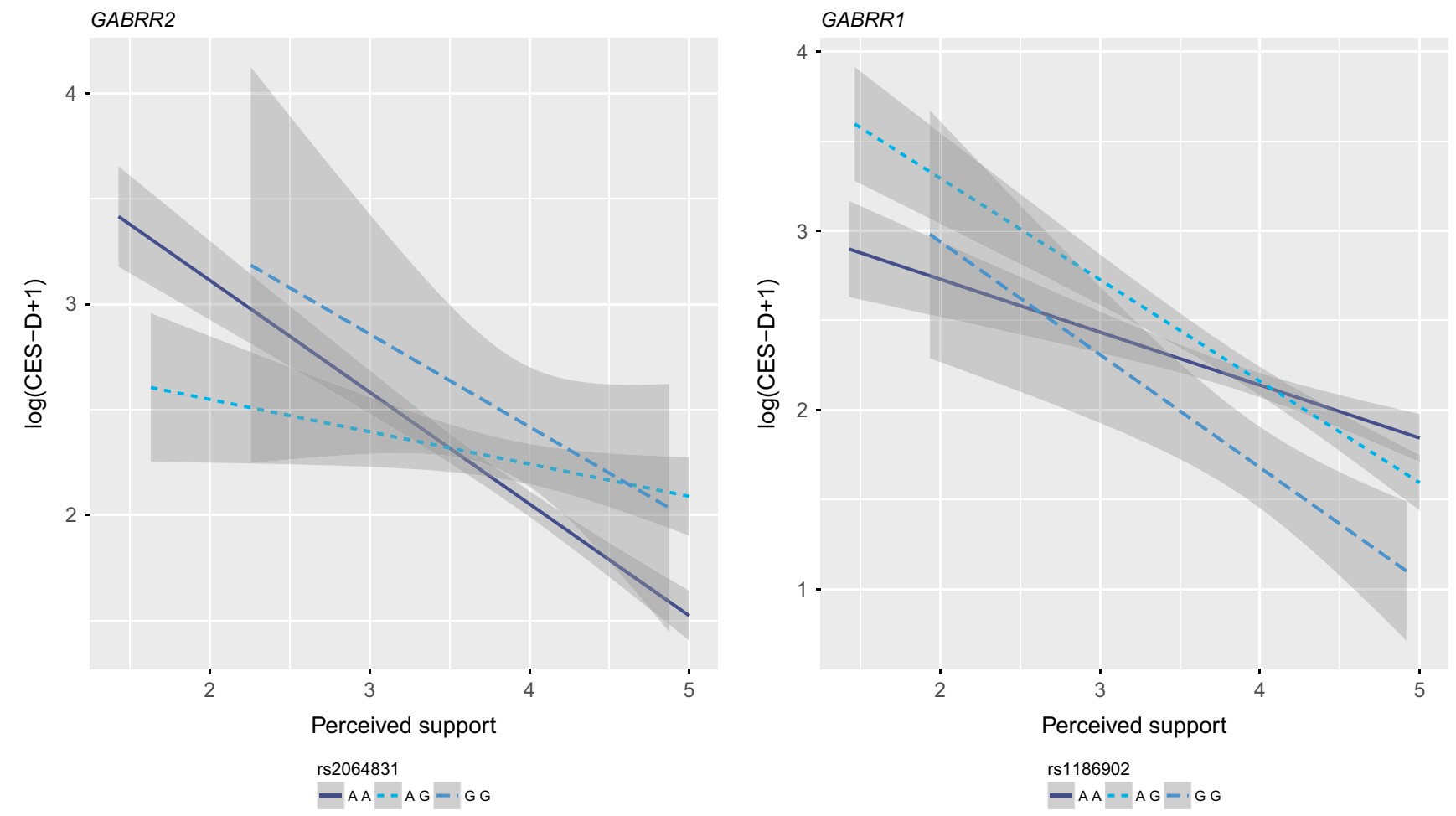

Figure 2 Interactions for the most significant SNPs of the most significant genes as identified by gene-based testing. Interaction of the different genotype groups of the SNP with the environment variable in explaining depressive symptoms. Statistical details of these SNPs are shown in Table 3 [Colour figure can be viewed at wileyonlinelibrary.com] 
of psychiatric phenotypes, we present a method that allows testing for gene-environment interactions in a polygenic dataset for a complex phenotype. We tested this approach in our dataset of approximately 1,000 adolescents, with reported depressive symptoms as outcome measure, and perceived parental support, psychological control, and harsh punishment as environmental exposures. After correction for multiple testing, we found evidence for two genes interacting with perceived support in association with depressive symptoms in adolescence. These genes appeared to be exposure-specific.

\section{Polygenic approach of a multifaceted environmental context}

This gene-based method represents an intuitive approach that extends the possibilities of $\mathrm{G} \times \mathrm{E}$ research and takes the field to the polygenic stage. To our knowledge, we are the first to use this method to identify genes involved in $\mathrm{G} \times \mathrm{E}$ interactions for psychiatric phenotypes. This approach summarizes the genetic information at the gene level. Therefore, the method can be used with realistic sample sizes that allow for an extensive and precise assessment of environmental exposures, which is a prerequisite for high-quality $\mathrm{G} \times \mathrm{E}$ research (Levinson et al., 2014; Ripke et al., 2013).

Our investigation of multiple environmental parameters in interaction with multiple polymorphisms shows how different aspects of an environmental exposure (i.e. parenting) can interact differently in a polygenic phenotype. Evidence for interaction was specifically present for perceived parental support. In spite of evidence for methylation differences attributed to positive parenting styles (Zhang \& Meaney, 2010), parental support is rarely investigated in geneenvironment interaction research.

\section{Biological interpretation of the findings}

Parental support interacted with two GABA-related genes (gamma-aminobutyric acid): GABRR1 and GABRR2 (both genes coding for subunits of the $\mathrm{GABA}_{\mathrm{A}}$-rho receptor, formerly known as $\mathrm{GABA}_{\mathrm{C}^{-}}$ receptor (Enz, 2001; D. Zhang, Pan, Awobuluyi, \& Lipton, 2001)). It is well-known that both $\mathrm{GABA}_{\mathrm{A}}$ and $\mathrm{GABA}_{\mathrm{A}}$-rho receptors are ionotropic receptors, but the exact mechanism of different subunits involved in the $\mathrm{GABA}_{\mathrm{A}}$-rho receptor function in the central nervous system remains unclear (Olsen \& Sieghart, 2009; Pétriz, Reyes-Haro, González-González, Miledi, \& Martínez-Torres, 2014; Yoon \& Lee, 2014).

Unlike most existing theories for depression and depressive symptoms that focus on serotonin and its transporter (Asberg, Thoren, Traskman, Bertilsson, \& Ringberger, 1976; Owens \& Nemeroff, 1994; Uher \& McGuffin, 2010; Whittington et al., 2004), these results seem to support recent findings showing
GABAergic involvement in depression (Guilloux et al., 2012; Lener et al., 2016; Luscher, Shen, \& Sahir, 2011; Möhler, 2012; Ren et al., 2016). The GABA hypothesis focuses predominantly on a GABA deficit associated with depression. In this hypothesis, the $\mathrm{GABA}_{\mathrm{A}}$ receptor is believed to play a key role in the development of such a GABA deficit (Luscher et al., 2011; Möhler, 2012). Our results suggest that GABA-related genes may facilitate GABA transmission and availability in a context of perceived support and act as a protective factor when it comes to adolescents' reported depressive symptoms.

\section{Limitations}

Although we believe that the method presented is a substantial contribution to the field, a number of assumptions and potential limitations need to be considered. First, each newly introduced method needs validation through simulation studies that allow researchers to estimate false-positive rates. The most important assumption of this method is that the phenotype is polygenic. Due to its focus on the gene level, all SNPs are considered simultaneously. Hence, the presence of single causal variants can be masked. Nevertheless, this study shows the multiple possibilities of studying $\mathrm{G} \times \mathrm{E}$ with an extended gene list in any kind of dataset. The method as it currently stands, facilitates a transparent analysis of genetic data, in which modifications and improvements through more complex modeling could be incorporated easily. Optimizing the use of the method for GWAS datasets or datasets where polymorphisms cannot be easily annotated, is our next step in validating this enrichment-based approach.

As a second remark, replication of our results is vital to confirm the involvement of genetic variation in GABA-related genes in moderating the effects of parenting on depressive symptoms. However, due to our specific selection of environmental variables, an exact replication of the gene-environment interactions was challenging. Nevertheless, there was some support for the GABRR2 $\times$ support interaction in our replication, given the marginally significant correlation of the beta estimates, and the significant gene-based interaction results in the combined discovery and replication samples. Moreover, the results also seem to indicate that the genetic main effect of the GRID2IP gene was unlikely identified by chance, as we found a high and significant correlation between the estimates. Furthermore, the analysis of the combined datasets that was applied is conceptually similar to an Individual Participant Data Meta-Analysis (IPDMA), which is considered the gold standard of meta-analysis. An IPDMA uses the individual patient data rather than summary statistics, thus increasing power and precision. However, the application of typical meta-analytical techniques such as estimating heterogeneity is not 
informative when $k=2$. Any estimates of $\tau^{2}$ and $I^{2}$ one might obtain, are untrustworthy. Therefore, we have opted not to refer to our combined analysis as a 'meta-analysis' and/or conduct formal analyses to estimate heterogeneity.

Further replications are required in order to increase the robustness of these findings. The limited number of genetic markers also created difficulties in obtaining a reliable estimate of population stratification based on MDS-plots. Additionally, we noticed that our environmental variable of interest (i.e. perceived parenting) was also prone to population stratification. This was probably due to cultural differences that co-occur with the underlying genetic population structure. To limit the impact of this 'cultural stratification' on our final results, we excluded all non-Caucasian participants.

Although we managed to increase power by looking at a gene-based level, power remains an important issue in any polygenic method. The power analysis was based on an alpha of .05, which is also the significance level we took into account for the SNPbased analysis prior to the actual gene-based analysis. As the power calculation does not take the correction for the 263 genes tested into account, the proposed power at a sample size of $N=800$ may be an overestimation, as the results of the replication analyses also seem to indicate. Also, it could be argued that there is a need for additional control for the number of environmental variables tested. Due to their high internal correlations, this would result in the need to control for two 'independent' tests, which would not have changed the reported results.

The self-report questionnaires used to assess the environmental variables and outcome parameters were completed at a single point in time; therefore, this can introduce a common source bias. Also, these results do not provide information that allows drawing causal conclusions. Additionally, self-report questionnaires can be prone to a number of biases, such as reporting bias, shared informant, and recall biases. We are also aware of the possibility of selection bias that comes along with population studies, as well as a possibility that psychological control and harsh punishment may yield missing values that are nonrandom in nature, due to the sensitive information the questionnaire is referring to.

\section{Conclusion}

By describing this method that allows researchers to investigate $\mathrm{G} \times \mathrm{E}$ interactions in a polygenic context, we showed that polygenic approaches are not only important to grasp the polygenic structure of the phenotype itself (Ripke et al., 2014; Smoller et al., 2013). They appear equally important in understanding the impact of different environmental factors in interaction with the individual's genetic background. Earlier candidate gene studies illustrated how genes can affect adolescents' susceptibility to both positive and negative environments (Belsky, BakermansKranenburg, \& van IJzendoorn, 2007). The next important step in $\mathrm{G} \times \mathrm{E}$ is to examine the interactions with multiple environmental variables in a polygenic manner and to gain insight into how different genes and polymorphisms affect susceptibility for disease as a function of different exposures. Further down this road, we can incorporate epistasis, gene-gene-environment interactions $(\mathrm{G} \times \mathrm{G} \times \mathrm{E})$, and more complex interactions and network modeling to increase our understanding of susceptibility for the environment at the genomic level.

\section{Supporting information}

Additional Supporting Information may be found in the online version of this article:

Appendix S1. Extended supporting information

\section{Acknowledgements}

This research is funded by a Concerted Research Action grant (GOA/ 12/009) from the KU Leuven Research Fund. There was no influence of the funding agency in defining the study design, the collection, analysis and interpretation of data, nor was there any involvement in writing of the report or submission of the paper. S. C. and R. W. are Senior Clinical Investigators of the Fund for Scientific Research (FWO) Flanders. They thank the adolescents and the parents who participated in the study.

\section{Correspondence}

Evelien Van Assche, GRASP-Research Group, Department of Neuroscience, KU Leuven, Kapucijnenvoer 33g, 3000 Leuven, Belgium; Email: Evelien.vanassche@, uzleuven.be

\section{Key Points}

- Gene-based interaction analysis is a valid method for gene-environment analysis in a polygenic context.

- GABRR1 and GABRR2 interact with perceived support, pointing at GABA involvement in depressive symptoms.

- The finding of GABRR2 was also partly supported by a replication in an independent dataset.

- For one phenotype, different genes interact differently with different aspects of environmental exposure. This highlights the importance of a polygenic method that allows for discrimination at the gene level and stresses the importance of thoroughly assessing the environment for $\mathrm{G} \times \mathrm{E}$. 


\section{References}

Anderson, C.A., Pettersson, F.H., Clarke, G.M., Cardon, L.R., Morris, A.P., \& Zondervan, K.T. (2010). Data quality control in genetic case-control association studies. Nature Protocols, $5,1564-1573$.

Asberg, M., Thoren, P., Traskman, L., Bertilsson, L., \& Ringberger, V. (1976). "Serotonin depression" - A biochemical subgroup within the affective disorders? Science, 191, 478-480.

Barrett, J.C., Fry, B., Maller, J., \& Daly, M.J. (2005). Haploview: Analysis and visualization of $\mathrm{LD}$ and haplotype maps. Bioinformatics, 21, 263-265.

Belsky, J., Bakermans-Kranenburg, M.J., \& van IJzendoorn, M.H. (2007). For better and for worse: Differential susceptibility to environmental influences. Current Directions in Psychological Science, 16, 300-304.

Brown, M.B. (1975). A method for combining non-independent. One-sided tests of significance. Biometrics, 31, 987.

Cantor, R.M., Lange, K., \& Sinsheimer, J.S. (2010). Prioritizing GWAS results: A review of statistical methods and recommendations for their application. The American Journal of Human Genetics, 86, 6-22.

Caspi, A., Sugden, K., Moffitt, T.E., Taylor, A., Craig, I.W., Harrington, H., ... \& Poulton, R. (2003). Influence of life stress on depression: Moderation by a polymorphism in the 5-HTT gene. Science, 301, 386-389.

Chorpita, B.F., Yim, L., Moffitt, C., Umemoto, L.A., \& Francis, S.E. (2000). Assessment of symptoms of DSM-IV anxiety and depression in children: A revised child anxiety and depression scale. Behaviour Research and Therapy, 38, 835-855. Retrieved from http://www.ncbi.nlm.nih.gov/pubmed/ 10937431

Curwen, V., Eyras, E., Andrews, T.D., Clarke, L., Mongin, E., Searle, S.M.J., \& Clamp, M. (2004). The Ensembl automatic gene annotation system. Genome Research, 14, 942-950.

Duncan, L.E., \& Keller, M.C. (2011). A critical review of the first 10 years of candidate gene-by-environment interaction research in psychiatry. The American Journal of Psychiatry, 168, 1041-1049.

Dunn, E.C., Uddin, M., Subramanian, S.V., Smoller, J.W., Galea, S., \& Koenen, K.C. (2011). Research review: Geneenvironment interaction research in youth depression - a systematic review with recommendations for future research. Journal of Child Psychology and Psychiatry, 52, 1223-1238.

Enz, R. (2001). GABA(C) receptors: A molecular view. Biological Chemistry, 382, 1111-1122.

Fisher, R.A. (1932). Statistical methods for research workers (4th Ed.). Edinburgh: Oliver and Boyd, 1925.

Flint, J., \& Kendler, K.S. (2014). The genetics of major depression. Neuron, 81, 484-503.

Franceschini, A., Szklarczyk, D., Frankild, S., Kuhn, M., Simonovic, M., Roth, A., ... \& Jensen, L.J. (2013). STRING v9.1: Protein-protein interaction networks, with increased coverage and integration. Nucleic Acids Research, 41(Database issue), D808-D815.

Guilloux, J.-P., Douillard-Guilloux, G., Kota, R., Wang, X., Gardier, A.M., Martinowich, K., ... \& Sibille, E. (2012). Molecular evidence for BDNF- and GABA-related dysfunctions in the amygdala of female subjects with major depression. Molecular Psychiatry, 17, 1130-1142.

Hill, W.G., Goddard, M.E., \& Visscher, P.M. (2008). Data and theory point to mainly additive genetic variance for complex traits. PLoS Genetics, 4, e1000008.

Hyde, C.L., Nagle, M.W., Tian, C., Chen, X., Paciga, S.A., Wendland, J.R., . . \& \& Winslow, A.R. (2016). Identification of 15 genetic loci associated with risk of major depression in individuals of European descent. Nature Genetics, 48, 10311036.

Janssens, A., Goossens, L., Van Den Noortgate, W., Colpin, H., Verschueren, K., \& Van Leeuwen, K. (2015). Parents' and adolescents' perspectives on parenting: Evaluating conceptual structure, measurement invariance, and criterion validity. Assessment, 22, 473-489.

Keers, R., Coleman, J.R.I., Lester, K.J., Roberts, S., Breen, G., Thastum, M., ... \& Eley, T.C. (2016). A genome-wide test of the differential susceptibility hypothesis reveals a genetic predictor of differential response to psychological treatments for child anxiety disorders. Psychotherapy and Psychosomatics, 85, 146-158.

Keller, M.C. (2014). Gene $\times$ environment interaction studies have not properly controlled for potential confounders: The problem and the (simple) solution. Biological Psychiatry, 75, $18-24$.

Lahey, B.B. (2015). Why are children who exhibit psychopathology at high risk for psychopathology and dysfunction in adulthood? JAMA Psychiatry, 72, 865-866.

Lener, M.S., Niciu, M.J., Ballard, E.D., Park, M., Park, L.T., Nugent, A.C., \& Zarate, C.A. (2016). Glutamate and gammaaminobutyric acid systems in the pathophysiology of major depression and antidepressant response to ketamine. Biological Psychiatry, 81, 886-897.

Levinson, D.F., Mostafavi, S., Milaneschi, Y., Rivera, M., Ripke, S., Wray, N.R., \& Sullivan, P.F. (2014). Genetic studies of major depressive disorder: Why are there no genome-wide association study findings and what can we do about it? Biological Psychiatry, 76, 510-512.

Luscher, B., Shen, Q., \& Sahir, N. (2011). The GABAergic deficit hypothesis of major depressive disorder. Molecular Psychiatry, 16, 383-406.

Manolio, T.A., Collins, F.S., Cox, N.J., Goldstein, D.B., Hindorff, L.A., Hunter, D.J., . . \& Visscher, P.M. (2009). Finding the missing heritability of complex diseases. Nature, 461, 747-753.

Markus, M.T., Lindhout, I.E., Boer, F., Hoogendijk, T.H., \& Arrindell, W.A. (2003). Factors of perceived parental rearing styles: The EMBU-C examined in a sample of Dutch primary school children. Personality and Individual Differences, 34, 503-519.

McLeod, G.F.H., Horwood, L.J., \& Fergusson, D.M. (2016). Adolescent depression, adult mental health and psychosocial outcomes at 30 and 35 years. Psychological Medicine, 46, 1401-1412.

McLeod, B.D., Weisz, J.R., \& Wood, J.J. (2007). Examining the association between parenting and childhood depression: A meta-analysis. Clinical Psychology Review, 27, 986-1003.

Möhler, H. (2012). The GABA system in anxiety and depression and its therapeutic potential. Neuropharmacology, 62, 4253.

Oldehinkel, A.J., Rosmalen, J.G., Buitelaar, J.K., Hoek, H.W., Ormel, J., Raven, D., .. \& H Hartman, C.A. (2015). Cohort profile update: The TRacking adolescents' individual lives survey (TRAILS). International Journal of Epidemiology, 44, 76-76n.

Olsen, R.W., \& Sieghart, W. (2009). GABA A receptors: Subtypes provide diversity of function and pharmacology. Neuropharmacology, 56, 141-148.

Owens, M., \& Nemeroff, C. (1994). Role of serotonin in the pathophysiology of depression: Focus on the serotonin transporter. Clinical Chemistry, 40, 288-295. Retrieved from http://www.clinchem.org/content/40/2/ 288. short.

Pétriz, A., Reyes-Haro, D., González-González, M.A., Miledi, R., \& Martínez-Torres, A. (2014). GABA $\rho$ subunits confer a bicuculline-insensitive component to GFAP+ cells of cerebellum. Proceedings of the National Academy of Sciences of the United States of America, 111, 17522-17527.

Peyrot, W.J., Lee, S.H., Milaneschi, Y., Abdellaoui, A., Byrne, E.M., Esko, T., .. \& \& Penninx, B.W.J.H. (2015). The association between lower educational attainment and depression owing to shared genetic effects? Results in 25000 subjects Molecular Psychiatry, 20, 735-743. 
Plomin, R. (2013). Commentary: Missing heritability, polygenic scores, and gene-environment correlation. Journal of Child Psychology and Psychiatry, and Allied Disciplines, 54, $1147-$ 1149.

Purcell, S., Neale, B., Todd-Brown, K., Thomas, L., Ferreira, M.A.R., Bender, D., .. \& \& Sham, P.C. (2007). PLINK: A tool set for whole-genome association and population-based linkage analyses. The American Journal of Human Genetics, 81, 559-575.

Purcell, S.M., Wray, N.R., Stone, J.L., Visscher, P.M., O’Donovan, M.C., Sullivan, P.F., \& Sklar, P. (2009). Common polygenic variation contributes to risk of schizophrenia and bipolar disorder. Nature, 460, 748-752.

R Development Core Team. (2008). R: A language and environment for statistical computing. Vienna, Austria: R Foundation for Statistical Computing. Retrieved from https://www. r-project.org/

Radloff, L.S. (1977). The CES-D Scale: A Self-Report Depression Scale for research in the general population. Applied Psychological Measurement, 1, 385-401.

Ren, Z., Pribiag, H., Jefferson, S.J., Shorey, M., Fuchs, T., Stellwagen, D., \& Luscher, B. (2016). Bidirectional homeostatic regulation of a depression-related brain state by gamma-aminobutyric acidergic deficits and ketamine treatment. Biological Psychiatry, 80, 457-468.

Ripke, S., Neale, B.M., Corvin, A., Walters, J.T.R., Farh, K.-H., Holmans, P.A., ... \& O’Donovan, M.C. (2014). Biological insights from 108 schizophrenia-associated genetic loci. Nature, 511, 421-427.

Ripke, S., Wray, N.R., Lewis, C.M., Hamilton, S.P., Weissman, M.M., Breen, G., .. \& \& Sullivan, P.F. (2013). A mega-analysis of genome-wide association studies for major depressive disorder. Molecular Psychiatry, 18, 497-511.

Smedley, D., Haider, S., Durinck, S., Pandini, L., Provero, P., Allen, J., .. \& \& Kasprzyk, A. (2015). The BioMart community portal: An innovative alternative to large, centralized data repositories. Nucleic Acids Research, 43(W1), W589-W598.

Smoller, J.W., Craddock, N., Kendler, K., Lee, P.H., Neale, B.M., Nurnberger, J.I., . . \& Sullivan, P.F. (2013). Identification of risk loci with shared effects on five major psychiatric disorders: A genome-wide analysis. Lancet, 381, 1371-1379.

Uher, R., \& McGuffin, P. (2010). The moderation by the serotonin transporter gene of environmental adversity in the etiology of depression: 2009 update. Molecular Psychiatry, 15, 18-22.

Van Assche, E., Moons, T., Van Leeuwen, K., Colpin, H., Verschueren, K., Van Den Noortgate, W., ... \& Claes, S.
(2016). Depressive symptoms in adolescence: The role of perceived parental support, psychological control, and proactive control in interaction with 5-HTTLPR. European Psychiatry: The Journal of the Association of European Psychiatrists, 35, 55-63.

Viding, E. (2013). Commentary: Study of gene-environment interplay - A lesson in how to keep oneself busy for the foreseeable future. Journal of Child Psychology and Psychiatry, 54, 1144-1146.

Vinkhuyzen, A.A.E., \& Wray, N.R. (2014). Novel directions for $\mathrm{G} \times \mathrm{E}$ analysis in psychiatry. Epidemiology and Psychiatric Sciences, 24, 12-19.

Whittington, C.J., Kendall, T., Fonagy, P., Cottrell, D., Cotgrove, A., \& Boddington, E. (2004). Selective serotonin reuptake inhibitors in childhood depression: Systematic review of published versus unpublished data. Lancet, 363, $1341-1345$.

Winham, S.J., \& Biernacka, J.M. (2013). Gene-environment interactions in genome-wide association studies: Current approaches and new directions. Journal of Child Psychology and Psychiatry, 54, 1120-1134.

van Winkel, R. (2015). Aetiological stratification as a conceptual framework for gene-by-environment interaction research in psychiatry. Epidemiology and Psychiatric Sciences, 24, 6-11.

Wray, N.R., Lee, S.H., Mehta, D., Vinkhuyzen, A.A.E., Dudbridge, F., \& Middeldorp, C.M. (2014). Research Review: Polygenic methods and their application to psychiatric traits. Journal of Child Psychology and Psychiatry, 55, 1068-1087.

Yoon, B.-E., \& Lee, C.J. (2014). GABA as a rising gliotransmitter. Frontiers in Neural Circuits, 8, 141.

Zannas, A.S., \& Binder, E.B. (2014). Gene-environment interactions at the FKBP5 locus: Sensitive periods, mechanisms and pleiotropism. Genes, Brain and Behavior, 13, 25-37.

Zhang, T.-Y., \& Meaney, M.J. (2010). Epigenetics and the environmental regulation of the genome and its function. Annual Review of Psychology, 61, 439-466, C1-3.

Zhang, D., Pan, Z.-H., Awobuluyi, M., \& Lipton, S.A. (2001). Structure and function of GABAC receptors: A comparison of native versus recombinant receptors. Trends in Pharmacological Sciences, 22, 121-132.

Accepted for publication: 25 April 2017

First published online: 28 June 2017 